\title{
Risk advantages and information acquisition
}

\author{
Thomas R. Palfrey*
}

In some competitive situations under uncertainty, less risk averse competitors have an advantage over more risk averse opponents. Private information acquisition by the advantaged players diminishes this advantage by reducing the risk faced by their opponents in a Nash equilibrium. This tradeoff between risk advantages and informational advantages is examined in the context of a duopoly model with uncertain demand. It is found that private information acquisition may reduce the risk advantage by so much that the overall effect is to make the informed, less risk averse competitor worse off and the uninformed, more risk averse competitor better off.

\section{Introduction}

In recent years the comparison of economic behavior in environments which differ by the amount of private information possessed by different decisionmaking agents has been a topic of much concern. One of the more interesting observations that has been made is that private information not only is capable of producing market inefficiencies but may also be damaging to the agent possessing the information. This occurs in signalling models (Spence, 1974) and in adverse selection models (Akerlof, 1970; Wilson, 1978), and is a feature in game-theoretic models of limit pricing (Milgrom and Roberts, 1979), in general principal-agent problems (Green and Stokey, 1981), and in other settings (Ponssard, 1976).

A common thread that runs through these examples of detrimental private information is that public actions reveal an agent's private information. The other strategic participants in the market (players in the game) can then use this information in a way that leaves the player possessing private information worse off than would have been the case if there had been no private information. The typical scenario proceeds as follows: one player observes some private information, takes an action, and then the player who does not have private information (or has less information) makes a decision contingent on the informed player's action. Because the uninformed player can observe the informed player's action before selecting an action of his own, he is able to deduce, perhaps imperfectly, what the informed player's information is. Hence, in equilibrium the information is not completely private.

The purpose of this article is to explore a different class of games in which private information is harmful. First, the implicit sequencing of actions is not a critical element; both players move simultaneously and neither player's actions are contingent on the other's. Second, what is important is that the two players have different risk attitudes, and private information possessed by one player affects (in equilibrium) the risk faced by the other player.

In a number of games with uncertain payoffs, players who are less risk averse than their opponents will receive higher payoffs in equilibrium than will their more risk averse

\footnotetext{
* Carnegie-Mellon University.

I wish to thank Alvin Klevorick, Tom Lee, and a reader for The Bell Journal of Economics for helpful comments.
} 
opponents. ${ }^{1}$ This risk advantage may vary with the degree of all players' risk aversion and the amount of risk the players confront. If any player gains private information, this may reduce the risk in the distribution of equilibrium payoffs to all players. This will benefit the more risk averse players and may harm the less risk averse players. If one of the less risk averse players gains private information, he will gain an informational advantage over the other players, but it is quite possible that this advantage will be offset because of the reduction of risk faced by the opponents. In these situations there is a tradeoff between informational advantage and risk advantage.

This principle is illustrated by examining a simple Cournot duopoly game with demand uncertainty. Two competing firms share identical technologies and prior beliefs about the market demand curve for their product. They differ only in their attitudes toward risk. Two situations are compared. In the first both firms are equally informed about demand; in the second the less risk averse firm has perfect information about demand.

\section{The model}

The game studied is a static model of duopoly with uncertain demand in which the two competing firms independently and simultaneously make output decisions to maximize expected utility of profits. Each firm can produce unlimited quantities of a good, $x$, with no fixed cost and constant marginal cost, $c>0$. The demand curve for $x$ is linear:

$$
x(p)=\frac{a}{b}-\frac{1}{b} p, \quad a>0, \quad b>0 .
$$

The slope $(b)$ of the inverse demand curve is known to both firms, but the intercept $(a)$ is unknown. The distribution of $a$ is common knowledge to both firms. The distribution function, $F(a)$, is strictly increasing on some real interval $[A, B], B>A$, and has the following properties:

Assumption 1: $F(A)=0, F(B)=1$;

Assumption 2: $F$ is continuously differentiable on $[A, B]$ and denote $f=F^{\prime}$;

Assumption 3: $0<M_{1} \leq f(a) \leq M_{2}<\infty$ for all $a \in[A, B]$; and

Assumption 4: $A>2 c$.

The last two assumptions are made for technical convenience. Assumption 3 facilitates the analysis of limiting behavior when a firm becomes extremely risk averse; Assumption 4 will assure that, regardless of firms' risk attitudes, both firms will produce positive output in equilibrium.

Two separate informational situations are examined. In the first, the symmetric information game, each firm must choose an output level before observing $a$. In the second, the asymmetric information game, firm 1 observes demand perfectly before making a production decision, but firm 2 must still produce before observing $a$.

Profits of firm 1 are denoted by $\pi_{1}=\left[a-b\left(x_{1}+x_{2}\right)-c\right] x_{1}$ and profits of firm 2 are denoted $\pi_{2}=\left[a-b\left(x_{1}+x_{2}\right)-c\right] x_{2}$. Each firm maximizes expected utility of profits, where their von Neumann-Morgenstern utility functions are $u_{1}\left(\pi_{1}\right)$ and $u_{2}\left(\pi_{2}\right)$, respectively.

․ Symmetric game. Each firm chooses an output level to maximize expected utility of profits, given an output level chosen by the opponent firm. An equilibrium is defined as

\footnotetext{
${ }^{1}$ This is a feature of some bargaining models. See, for example, Sobel (1981).
} 
a pair of outputs $x_{1}^{*}, x_{2}^{*}$ such that $x_{1}^{*}$ is the expected utility maximizing output choice of firm 1 if firm 1 predicts that firm 2 will choose $x_{2}^{*}$, and vice versa. It should be pointed out that the only asymmetry in the model introduced so far is that the two firms in general may have different utility functions.

Because neither firm is able to observe the realization of $a, \hat{a}$, before choosing a level of output, the equilibrium choices of each firm do not depend on $\hat{a}$, but only on the distribution of $a$. The equilibrium is determined by the intersection of the two reaction curves obtained from the following two maximization problems.

Firm 1:

$$
\max _{x_{1}} \int_{A}^{B} u_{1}\left\{\left[a-b\left(x_{1}+x_{2}\right)-c\right] x_{1}\right\} f(a) d a .
$$

Firm 2:

$$
\max _{x_{2}} \int_{A}^{B} u_{2}\left\{\left[a-b\left(x_{1}+x_{2}\right)-c\right] x_{2}\right\} f(a) d a .
$$

Solving for the reaction functions yields the following two equations which, assuming second-order conditions are satisfied, implicitly characterize the equilibrium:

$$
\begin{aligned}
& x_{1}^{*}=\frac{1}{2 b}\left\{\int_{A}^{B} \frac{a u_{1}^{\prime}\left\{\left[a-b\left(x_{1}^{*}+x_{2}^{*}\right)-c\right] x_{1}^{*}\right\}}{\int_{A}^{B} u_{1}^{\prime}\left\{\left[t-b\left(x_{1}^{*}+x_{2}^{*}\right)-c\right] x_{1}^{*}\right\} f(t) d t} f(a) d a-b x_{2}^{*}-c\right\} \\
& x_{2}^{*}=\frac{1}{2 b}\left\{\int_{A}^{B} \frac{a u_{2}^{\prime}\left\{\left[a-b\left(x_{1}^{*}+x_{2}^{*}\right)-c\right] x_{2}^{*}\right\}}{\int_{A}^{B} u_{2}^{\prime}\left\{\left[t-b\left(x_{1}^{*}+x_{2}^{*}\right)-c\right] x_{2}^{*}\right\} f(t) d t} f(a) d a-b x_{1}^{*}-c\right\} .
\end{aligned}
$$

Asymmetric game. In the asymmetric information game, firm 1 observes $\hat{a}$ before making an output decision. Thus, for any predicted level of output by firm 2, firm 1 may choose different levels of output depending on $\hat{a}$. While firm 2 still has a strategy that is constant across all states of the world (i.e., all possible realizations of $a$ ), a strategy of firm 1 is now a function $x_{1}(\hat{a})$ which maps realizations of $a$ into output choices.

A Cournot-Nash equilibrium for this game is defined in a similar manner as before. Each firm is assumed to choose a strategy (output function for firm 1, output level for firm 2) to maximize expected utility, given a predicted strategy chosen by the other firm. Note that firm 1's prediction about firm 2's strategy is an output level, while firm 2's prediction about firm 1's strategy is an output function. The equilibrium is a pair $\left[\tilde{x}_{1}(\cdot), \tilde{x}_{2}\right]$ such that $\tilde{x}_{1}(\hat{a})$ is the utility maximizing choice of firm 1 if firm 1 predicts firm 2's strategy is $\tilde{x}_{2}$ and the outcome of the random variable is $\hat{a}$; and $\tilde{x}_{2}$ is the expected utility maximizing choice of firm 2 if firm 2 predicts that firm 1's strategy is $\tilde{x}_{1}(\cdot)$.

Firm 1's problem is to choose $x_{1}$, given $x_{2}$ and the realization of demand, $\hat{a}$, to maximize $u_{1}\left[\left(\hat{a}-b\left(x_{1}+x_{2}\right)-c\right) x_{1}\right]$. This is equivalent to maximizing profit since $u_{1}$ is increasing. Firm 2's problem is to choose $x_{2}$, given $x_{1}(\cdot)$, to maximize $\int_{A}^{B} u_{2}\left\{\left[a-b\left(x_{1}(a)+x_{2}\right)-c\right] x_{2}\right\} f(a) d a$. The reaction functions for the two firms, which together characterize the equilibrium, are:

$$
\begin{aligned}
\tilde{x}_{1}(\hat{a}) & =\frac{1}{2 b}\left[\hat{a}-b \tilde{x}_{2}-c\right] \\
\tilde{x}_{2} & =\frac{1}{2 b}\left\{\int_{A}^{B} \frac{u_{2}^{\prime}\left\{\left[a-b\left(\tilde{x}_{1}(a)+\tilde{x}_{2}\right)-c\right] \tilde{x}_{2}\right\}\left[a-b \tilde{x}_{1}(a)\right]}{\int_{A}^{B} u_{2}^{\prime}\left\{\left[t-b\left(\tilde{x}_{1}(t)+\tilde{x}_{2}\right)-c\right] \tilde{x}_{2}\right] f(t) d t} f(a) d a-c\right\} .
\end{aligned}
$$




\section{2 / THE BELL JOURNAL OF ECONOMICS}

A number of observations can now be made. First, it is an advantage to a firm to be less risk averse than the opponent firm in the symmetric information equilibrium. The reason for this is as follows: Suppose we define firm 2 as being more risk averse than firm 1 if and only if $u_{2}$ is an increasing concave transformation of $u_{1}$. It follows from a result in Diamond and Stiglitz (1974) that an increase (decrease) in a duopolist's risk aversion will cause a downward (upward) shift of his reaction curve. In the resulting equilibrium, that duopolist will have a lower (higher) output and his opponent will have a higher (lower) expected utility. In this sense the less risk averse duopolist has a risk advantage over the more risk averse duopolist. A firm is better off the less risk averse it is and the more risk averse its opponent is.

The second observation is that, ceteris paribus, a firm with a risk averse opponent is better off in equilibrium the more risk his opponent must face. This follows because given the structure of payoffs, greater risk induces a risk averse firm's reaction curve to shift downward.

Third, the equilibrium solution in the symmetric information game is a function of the risk attitudes of both players, while in the asymmetric information game it is a function only of the risk attitude of the uninformed player. Fourth, in the symmetric information game, players' strategies are unresponsive to true demand, while in the asymmetric information game the informed firm's output is positively correlated with demand.

From the first and third observation one can see that the less risk averse firm no longer enjoys the full beneficial strategic effects of its own risky behavior if it is informed, since its risk attitudes no longer affect its behavior. Furthermore, from the fourth observation one can see that an informed player reduces the risk faced by his opponent (since the informed player's own strategy is now correlated with demand). Since a firm competing against a risk averse opponent prefers his opponent to face more risk rather than less, this is detrimental to the informed firm.

Naturally, information about demand is useful to the firm in other ways, but to a sufficiently less risk averse firm the loss in its original risk advantage may more than offset the new informational advantage. This is demonstrated in two "extreme" examples below.

Example A: Firm 1 is risk neutral, firm 2 is a maximiner. ${ }^{2}$ The equilibria for the two games are, respectively, ${ }^{3}$

$$
\begin{aligned}
\left(x_{1}^{*}, x_{2}^{*}\right) & =\left(\frac{2 \bar{a}-A-c}{3 b}, \frac{2 A-\bar{a}-c}{3 b}\right) \\
\left(\tilde{x}_{1}(\hat{a}), \tilde{x}_{2}\right) & =\left(\frac{3 / 2 \hat{a}-1 / 2 A-c}{3 b}, \frac{A-c}{3 b}\right) .
\end{aligned}
$$

Since firm 1 is risk neutral, it is better off in the game that yields the highest expected profit. The expected profit to firm 1 in the symmetric information game is $(2 \bar{a}-A$ $-c)^{2} / 9 b$ and in the asymmetric game it is $\int_{A}^{B}(3 / 2 a-1 / 2 A-c)^{2} f(c) d c / 9 b$. The first expression is greater than the second for a wide variety of distributions (for example, if $a$ is symmetrically distributed around $\bar{a}$ ).

Example $B$ : Firm 1 is a maximaxer ${ }^{4}$ and firm 2 is risk neutral. Assume $\bar{a}>(B+c) /$ 2. The equilibria of the two games are, respectively:

\footnotetext{
${ }^{2}$ Firm 2 maximizes its minimum profit (i.e., the profit it receives if $a=A$ ).

${ }^{3}$ The expected value of $a$ is denoted $\bar{a}$.

${ }^{4}$ Firm 1 maximizes its maximum profit (i.e., the profit it receives if $a=B$ ).
} 


$$
\begin{aligned}
\left(x_{1}^{*}, x_{2}^{*}\right) & =\left(\frac{2 B-\bar{a}-c}{3 b}, \frac{2 \bar{a}-B-c}{3 b}\right) \\
\left(\tilde{x}_{1}(\hat{a}), \tilde{x}_{2}\right) & =\left(\frac{3 / 2 \hat{a}-1 / 2 \bar{a}-c}{3 b}, \frac{\bar{a}-c}{3 b}\right) .
\end{aligned}
$$

Since firm 1 is a maximaxer, it is better off in the game that yields the highest profit when $\hat{a}=B$. Maximum profit (when $\hat{a}=B$ ) to firm 1 in the symmetric information game is $(2 B-\bar{a}-c)^{2} / 9 b$ and in the asymmetric information game it is $(3 / 2 B-1 / 2 \bar{a}$ $-c)^{2} / 9 b$. Since $B>\bar{a}$, firm 1 is better off uninformed, regardless of the distribution of demand.

The intuitive arguments as to why information might hurt the informed, less risk averse firm also suggest that the more risk averse firm may prefer to play against an informed firm since that reduces the risk the more risk averse firm faces. This is illustrated below, using Examples A and B above.

In Example A, firm 2's minimum payoff is

$$
\pi_{2}=\frac{1}{9 b}(2 A-\bar{a}-c)^{2}
$$

if firm 1 does not gather information, and it is

$$
\pi_{2}^{\prime}=\frac{1}{9 b}(A-c)^{2}
$$

if firm 1 does gather information. Since $c<A<\bar{a}, \pi_{2}<\pi_{2}^{\prime}$, so that firm 2 is better off if firm 1 gathers information.

In Example B, firm 2's expected utility is just its expected profit which is

$$
\pi_{2}=\frac{1}{9 b}(2 \bar{a}-B-c)^{2}
$$

if firm 1 does not gather information, and it is

$$
\pi_{2}^{\prime}=\frac{1}{9 b}(\bar{a}-c)^{2}
$$

if firm 1 does gather information. Since $c<\bar{a}<B, \pi_{2}<\pi_{2}^{\prime}$, so that firm 2 is again better off if firm 1 gathers information.

In the foregoing examples, one of the firms had risk preferences that were extreme, so extreme that they could not be represented by a von Neumann-Morgenstern utility function. These preferences were used so that the solutions to the examples would be as simple as possible. Thus, it is important to note that the same conclusion, that the value of full information to the more risk averse firm can be negative, can be reached if less extreme risk preferences are used. In Example A, if firm 2 was not a maximiner but was still very risk averse, then a similar result would obtain. This would be the case if firm 2 had a utility function of the form $u_{2}(\pi)=-e^{-r \pi}$ for sufficiently large $r$, since maximining behavior is the limit of very risk averse behavior. Similarly, in Example B, if firm 1 was very risk preferring (i.e., "almost" a maximaxer), then a similar result would obtain. Thus the value of information can be negative when both agents have standard von Neumann-Morgenstern utility functions. A more formal argument is contained in an appendix, which is available from the author upon request.

\section{Discussion}

This article has shown that in some competitive environments free, private, fully appropriable information may not be valuable if it changes the risk faced by the other players. Precisely which environments constitute this set is an open question. 
Several points were made, however, that suggest that these findings apply, beyond the simple model of duopoly presented here, to a wide variety of economic games in which it is advantageous to impose risk on one's opponents and in which there is an advantage to playing against more risk averse opponents. Along similar lines, in situations in which it is advantageous not to impose risk on the opponent or in which one is better off facing less risk averse opponents, the effects could be reversed. That is, the more risk averse players would sacrifice a risk advantage when they became informed.

In many economic problems, for example, the study of auctions, games with incomplete information are used as a technique for analyzing equilibrium behavior. In such games, the risk attitudes of the players play an important role in affecting the equilibrium. Analysis usually proceeds by assuming, often for reasons of "analytical convenience," that players have risk neutral or at least identical risk preferences. This article suggests that relaxing these convenient assumptions will lead to some interesting and different conclusions, particularly regarding incentives for information acquisition.

\section{References}

AKERlof, G. “The Market for 'Lemons': Qualitative Uncertainty and the Market Mechanism." Quarterly Journal of Economics, Vol. 84 (1970), pp. 488-500.

Diamond, P. ANd Stiglitz, J. “Increases in Risk and Risk Aversion." Journal of Economic Theory, Vol. 8 (July 1974), pp. 337-360.

Green, J. AND Stokey, N. "The Value of Information in the Delegation Problem." Harvard Institute of Economic Research Discussion Paper \#776, September 1981.

HiRshleifER, J. "The Private and Social Value of Information and the Reward to Inventive Activity." American Economic Review, Vol. 61 (September 1971), pp. 561-574.

Matthews, S. "Information Acquisition in Discriminatory Auctions." Working Paper, University of Illinois at Champaign-Urbana, Department of Economics, 1979.

Milgrom, P. "Rational Expectations, Information Acquisition and Competitive Bidding." Econometrica, Vol. 49 (July 1981), pp. 921-943.

- AND Roberts, J. “Equilibrium Limit Pricing Doesn't Limit Entry.” Econometrica, Vol. 50 (March 1982), pp. 443-459.

- AND WEBer, R. "Information, Bidder Profits, and Seller Revenues in Auctions." Unpublished Manuscript, Northwestern University, 1980.

PONSSARD, J.-P. "On the Concept of the Value of Information in Competitive Situations." Management Science, Vol. 22 (March 1976), pp. 739-747.

Sobel, J. "Distortion of Utilities and the Bargaining Problem.” Econometrica, Vol. 49 (May 1981), pp. 597620.

SPENCE, A.M. Market Signalling. Cambridge: Harvard University Press, 1974.

WiLSON, R. "Information, Efficiency, and the Core of an Economy." Econometrica, Vol. 46 (July 1978), pp. 807-816. 